\title{
Cuando las personas que consumen drogas inyectadas tienen la palabra: Análisis cualitativo de contenido temático sobre la percepción de uso de una aplicación móvil para los programas de intercambio de jeringas
}

\author{
When people who inject drugs speak: Qualitative \\ thematic analysis of the perception of a mobile \\ app for needle exchange programs
}

\author{
Fran Calvo*,**, Xavier Carbonell***, Mercè Rived****, Cristina Giralt** \\ * Grupo de Investigación en Salud Mental y Adicciones, [IdIBGi], Institut d'Assistència Sanitària, Girona. \\ ** Departament de Pedagogia, Universitat de Girona. \\ *** FPCEE Blanquerna, Universitat Ramon Llull, Barcelona. \\ **** Escola Universitària d'Infermeria i Teràpia Ocupacional, EUIT, Universitat Autònoma de Barcelona.
}

\section{Resumen}

España es el país de Europa Occidental con más prevalencia del Virus de la Inmunodeficiencia Humana entre personas que se inyectan drogas. La presencia de Virus de la Hepatitis-C supera el cincuenta por ciento en esta población. Al mismo tiempo, la Organización Mundial de la Salud considera que la cobertura media de material de inyección por usuario y año es baja. Con más de treinta años de experiencia en el despliegue de los servicios y programas de reducción de daños, las ventajas que posibilita la eSalud y la mSalud como la accesibilidad y asequibilidad, pueden incorporarse también a la reducción de daños. El objetivo de este estudio fue analizar la percepción que las personas que consumen drogas inyectadas tienen sobre una aplicación móvil para mejorar el acceso a material de inyección. Partiendo de un enfoque cualitativo se recogió información a través de cinco grupos focales en los que participaron 51 personas consumidoras de drogas inyectadas en activo. Se llevó a cabo un análisis de contenido temático cuyos principales resultados indicaron que la aplicación tuvo una buena aceptación y se consideró sencilla y útil. Los participantes refirieron que la aplicación contribuía a mejorar el acceso a material de inyección, a reducir el estigma de los drogodependientes, y a optimizar la planificación del usuario para adquirir la jeringa en el proceso ritual del consumo. Como puntos a mejorar, destacaron reducir el exceso de información preventiva y simplificar la ruta de descarga de la webapp. En conclusión, la aplicación se posiciona como una herramienta útil para complementar la intervención ordinaria de los programas de intercambio de jeringas.

Palabras clave: Reducción de daños; programa de intercambio de jeringas; consumo de drogas; eSalud; mSalud; drogas ilícitas; cocaína; heroína; grupo focal.

\begin{abstract}
Spain is the Western European country with the highest prevalence of Human Immunodeficiency Virus among people who inject drugs. The Hepatitis-C Virus affects over fifty per cent of this population. At the same time, the World Health Organization considers that the average coverage of injection material for drug user per year is low. Harm reduction programs and services have been deployed for over thirty years, and these could now incorporate the advantages of eHealth and mHealth to improve harm reduction. The aim of this qualitative and descriptive study is to analyze how people who inject drugs perceive an application for mobile devices. Fifty-one such drug users participated actively in five focus groups. The main results of the thematic content analysis indicated that the application was welcomed as easy and useful. Participants reported that the application contributed to improving access to injection material, reducing the stigma of drug-dependence and optimizing the organization of the ritual of injection. Excessive preventive information and problems downloading the web app were identified as aspects for improvement. In conclusion, the application was seen as a useful eHealth tool that complements the normal intervention of needle exchange programs.

Keywords: Harm reduction; needle exchange programs; drug consumption; eHealth; mHealth; illicit drugs; cocaine; heroin; focus group.
\end{abstract}




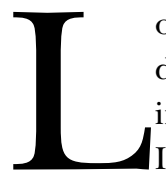

os principales daños asociados a los consumos de drogas inyectadas son la sobredosis letal y la infección de enfermedades como el Virus de la Inmunodeficiencia Humana (VIH) y el Virus de la Hepatitis-C (VHC) (Folch et al., 2016). Una de las intervenciones en reducción de daños (REDAN) que ha demostrado más eficacia y efectividad para disminuir las infecciones del VIH y el VHC es el programa de intercambio de jeringuillas (PIJ) (Platt et al., 2018). Aunque el nombre del programa hace referencia a la jeringa en sí, el PIJ proporciona a la persona que consume drogas por vía parenteral (PCDVP) el material necesario para realizar una inyección segura (filtros, recipientes, agua estéril, compresas impregnadas de alcohol). Este material, denominado parafernalia de inyección, ha demostrado ser especialmente eficaz en la reducción de dichas infecciones (Page, Morris, Hahn, Maher y Prins, 2013).

En la Unión Europea la tasa de infección del VIH es de 6,3 casos por cada 100.000 habitantes mientras que en España es de 9,4 casos por cada 100.000 habitantes y el 2,8\% del total de los casos de infección se debe al consumo intravenoso de drogas (Elattabi, Ruiz-Algueró, Hernando y Díaz, 2017). Respeto al VHC, España se encuentra entre los países europeos con una prevalencia estimada de personas con anticuerpos más elevada, con un porcentaje del 1,7\% sobre el total de personas adultas (Buti et al., 2017). El 23\% de los nuevos casos de infección de VHC están relacionados con el consumo inyectado de drogas (World Health Organization, 2017).

La prevalencia del VIH en el conjunto de PCDVP en España es la más elevada de Europa occidental (31,5\%) seguido por Italia $(28,8 \%)$. El Reino Unido, Malta, Finlandia, y Noruega presentan porcentajes inferiores al $2 \%$ (Stone, 2018). Respecto al VHC, España es el cuarto país con una prevalencia de infección más elevada de Europa Occidental $(53,3 \%)$ después de Portugal $(65,8 \%)$, Suecia (61,3\%) y Luxemburgo (61\%) (Grebely et al., 2019).

$\mathrm{Al}$ inicio de los años noventa, España alcanzó las prevalencias más altas de infección del VIH y de mortalidad asociada al Síndrome de la Inmunodeficiencia Adquirida entre PCDVP, debido mayoritariamente al consumo de heroína inyectada (Fuente et al., 2006). En parte motivado por esta situación, se crearon los cimientos de la red de atención a las drogodependencias y los servicios y programas REDAN, como el PIJ, que han conseguido reducir nuevas infecciones año tras año (Bosque-Prous y Brugal, 2016).

La efectividad del PIJ está determinada por una buena distribución de material de inyección entre PCDVP. La Organización Mundial de la Salud considera que una buena cobertura de kits de inyección por PCDVP/año es una estrategia clave en la prevención de las infecciones (Organización Mundial de la Salud, 2016). Según este mismo informe, en la actualidad nos encontramos en una situación de cobertura baja de jeringas estériles con un $5 \%$ de distribución desde los servicios de salud respecto las necesidades por PCDVP y año. En su estrategia contra la infección de enfermedades víricas incluye multiplicar por 10 el porcentaje de cobertura, hasta el $50 \%$, en el año 2020 y aumentar 40 puntos más, hasta el $90 \%$ de cobertura, en el año 2030. La información que tiene la PCDVP de los recursos disponibles en su comunidad y, en este caso, de los servicios que son puntos adscritos al PIJ es esencial para mejorar la cobertura de material de inyección.

En los últimos años hemos sido testigos del avance de las tecnologías de la información y la comunicación (TIC) y de su aplicabilidad en forma de aplicaciones eSalud o mSalud para dispositivos fijos o móviles para el tratamiento de las adicciones (Riper et al., 2018). Se entiende como eSalud la incorporación de las TIC a los cuidados sanitarios, tanto en la atención como en la promoción y la prevención de la salud (Eysenbach, 2001). La mSalud (mHealth -Mobile Health), hace referencia al mismo uso, pero a través de dispositivos móviles y sus correspondientes aplicaciones (app) (Kay, Santos y Takane, 2011).

En ausencia de aplicaciones específicas del PIJ, en el año 2017 se creó una aplicación para teléfonos inteligentes con el propósito de mejorar la accesibilidad de PCDVP a material de inyección. El objetivo principal de este estudio es analizar y describir la experiencia subjetiva de un grupo de personas que consumen drogas inyectadas respecto del uso de esta aplicación. Por ello se llevó a cabo diseño de metodología cualitativa de enfoque descriptivo. Los propósitos específicos de esta investigación son i) analizar la experiencia de uso de la aplicación en la comunidad autónoma de Cataluña en España; ii) comprender qué elementos del diseño y la usabilidad de esta app se presentan como facilitadores o barreras para comprometerse con las características de la aplicación; iii) explorar la percepción de las PCDVP sobre cómo la aplicación afectó o podría afectar en su comportamiento relacionado con el acceso a material de inyección; y iv) identificar futuras implicaciones de la aplicación en el PIJ.

\section{Método}

\section{Diseño general de la investigación}

Se llevó a cabo un estudio cualitativo descriptivo mediante el desarrollo y análisis de grupos focales. El grupo focal es una técnica de investigación que consiste en una forma de entrevista grupal en la que se crea una interacción entre investigadores y participantes para generar un espacio seguro donde expresar puntos de vista y opiniones, para acceder a información sobre el captar, sentir, vivir y percibir de los individuos respecto a un tópico (Flick, 2004). Dado que el objetivo de la investigación era conocer y describir las percepciones de las PCDVP sobre el uso de la tecnología móvil aplicada a la reducción de daños asociados a los consumos de drogas, se consideró que los grupos 
focales eran una estrategia más adecuada que estrategias individuales (Quintana y Montgomey, 2006). Este tipo de diseño se ha utilizado con éxito en el análisis de aplicaciones móviles con personas en situación de exclusión social extrema (Sheoran et al., 2016) y está recomendado en el estudio de medios de comunicación, incluidas las TIC (Morgan y Krueger, 1989).

\section{Participantes}

Participaron 51 PCDVP distribuidas en cinco grupos focales que se llevaron a cabo entre los meses de febrero y marzo de 2019. De los 51 participantes, el 84,6\% fueron hombres y la media de edad fue de 36,7 años $(\mathrm{DE}=7,5)$ con un rango comprendido entre 28 y 51 años. El $75 \%$ eran de procedencia autóctona y el resto inmigrantes, de los cuales 9 (17,3\% del total) eran del Magreb. Todos los participantes sabían leer y escribir y el $65 \%$ refirieron no tener estudios o tener estudios primarios. El 41,4\% se encontraban en algún tipo de situación de sinhogarismo: viviendo en albergues específicos para personas sin hogar, en casas ocupadas o en la calle, pernoctando en instituciones de forma intermitente. El consumo inyectado principal fue de cocaína $(44,2 \%)$, heroína $(34,7 \%)$ y speedball $(21,1 \%)$. Se pueden consultar los datos sociodemográficos de cada grupo focal en la Tabla 1.

Los participantes se reclutaron entre enero y febrero de 2019, en cinco contextos donde las PCDVP acudían a consumir drogas y que los equipos de intervención en medio abierto conocían: una zona de consumo habitual en las afueras de la ciudad de Girona que tiene un PIJ ubicado en un centro de atención primaria de salud, dos centros de tratamiento, un servicio móvil de reducción de daños y en un centro de atención a personas sin-hogar. De cada contexto surgió un grupo focal. El equipo de investigación y un grupo de estudiantes universitarias, todos ellos implicados en el proyecto de creación y desarrollo de la aplicación, acudieron a estos puntos para ofrecer a los participantes la posibilidad de participar en los grupos focales.

Se realizó un muestreo acumulativo, secuencial (para conseguir la saturación del discurso) y discrecional entre las personas que se consideró que podían explicar mejor la experiencia del uso de la aplicación (Rodríguez, Gil y Garda, 1996). Así, se trató de un muestreo no probabilístico por conveniencia. Los participantes se seleccionaron siguiendo los siguientes criterios de inclusión: i) que hubiesen usado la aplicación durante la prueba piloto; ii) usuarios mayores de edad, iii) consumidores de drogas inyectadas en activo; iv) en posesión de un teléfono inteligente; y v) que aceptaran participar voluntariamente en los grupos focales.

Dos investigadores con formación en psicología y psicopedagogía, uno especialista en investigación cualitativa y conducción de grupos focales y el otro en adicciones y reducción de daños llevaron a cabo los cinco grupos focales y registraron la información. En el análisis de los datos colaboraron dos expertos en metodología cualitativa y uno especialista en reducción de daños y eSalud.

Los tres especialistas en investigación cualitativa eran ajenos a la intervención especializada en reducción de daños. Su cometido principal fue el de garantizar una estructura sólida y garante de calidad en el proceso de diseño de la investigación, registro y análisis de datos. Los dos especialistas en reducción de daños y adicciones, tenían relación previa con los participantes como profesionales de reducción de daños asociados al consumo de drogas, cosa que posibilitó el reclutamiento y la retención de los participantes. Los investigadores cosupervisaron e intersupervisaron el proceso en las dinámicas de desarrollo de los grupos y la interpretación de los resultados, de forma continua para generar un proceso transparente y objetivo en la codificación, expresión de temas e interpretación de resultados.

Tabla 1. Características de los grupos focales.

\begin{tabular}{|c|c|c|c|c|c|c|c|c|c|c|c|c|c|c|}
\hline \multirow{2}{*}{$\begin{array}{l}\text { Código } \\
\text { grupo }\end{array}$} & \multirow{2}{*}{$\begin{array}{c}\text { Participantes } \\
\text { n (\%) }\end{array}$} & \multicolumn{2}{|c|}{ Sexo, n (\%) } & \multicolumn{2}{|c|}{ Procedencia, n (\%) } & \multicolumn{3}{|c|}{ Nivel estudios n (\%) } & \multirow{2}{*}{$\begin{array}{l}\text { Vivienda } \\
\text { propia } \\
\text { o de la } \\
\text { familia }\end{array}$} & \multirow{2}{*}{$\begin{array}{l}\text { Exclusión } \\
\text { residen- } \\
\text { cial }\end{array}$} & \multirow{2}{*}{$\begin{array}{l}\text { Edad } \\
\text { M(DE), } \\
\text { Rango }\end{array}$} & \multicolumn{3}{|c|}{$\begin{array}{c}\text { Consumo inyectado principal } \\
\mathrm{n}(\%)\end{array}$} \\
\hline & & Hombre & Mujer & Autóctono & Inmigrante & $\begin{array}{l}\text { Primarioso } \\
\text { sin estudios }\end{array}$ & $\begin{array}{c}\text { Secundarios o } \\
\text { formación } \\
\text { profesional }\end{array}$ & Superiores & & & & Heroína & Cocaína & $\begin{array}{l}\text { Speed- } \\
\text { ball }\end{array}$ \\
\hline GF1 & $8(15,4)$ & $7(13,5)$ & $1(1,9)$ & $7(14,3)$ & $1(1,9)$ & $6(11,4)$ & $1(1,9)$ & $1(1,9)$ & $6(11,5)$ & $2(3,8)$ & $39,9(6,3), 30-47$ & $3(5,8)$ & $4(7,7)$ & $1(1,9)$ \\
\hline $\mathrm{GF}_{3}$ & $11(21,6)$ & $8(15,4)$ & $3(5,9)$ & $9(17,3)$ & $2(3,8)$ & $7(14,3)$ & $4(7,7)$ & $0(0)$ & $6(11,5)$ & $5(9,6)$ & $37,1(7,7), 25.51$ & $3(5,8)$ & $6(11,5)$ & $2(3,8)$ \\
\hline $\mathrm{GF}_{4}$ & $9(17,3)$ & $9(17,3)$ & $0(0)$ & $6(12,4)$ & $3(5,9)$ & $5(9,5)$ & $3(5,9)$ & $1(1,9)$ & $0(0)$ & $9(18,3)$ & $40,6(2,8), 36-45$ & $2(3,8)$ & $4(7,7)$ & $3(5,8)$ \\
\hline $\mathrm{GF}_{5}$ & $11(21,6)$ & $10(19,2)$ & $2(3,8)$ & $8(15,5)$ & $3(5,9)$ & $7(14,3)$ & $3(5,9)$ & $1(1,9)$ & $9(17,3)$ & $2(3,8)$ & $37,4(7,4), 26-45$ & $4(7,7)$ & $5(9,6)$ & $3(5,8)$ \\
\hline Total & $52(100)$ & $44(84,6)$ & $8(15,4)$ & $39(75)$ & $13(25)$ & $33(65)$ & $15(29,1)$ & $3(5,9)$ & $31(58,6)$ & $21(41,4)$ & $36,7(7,5), 28-51$ & $18(34,7)$ & $23(44,2)$ & $11(21,1)$ \\
\hline
\end{tabular}




\section{Procedimiento}

\section{Descripción secuencial de las fases de desarrollo del proyecto PixApp}

El desarrollo técnico y comunitario de la aplicación denominada PixApp, forma parte de un proyecto de mejora de la atención en reducción de daños de l'Institut d'Assistència Sanitària, una empresa pública que presta servicios de salud mental y adicciones en la provincia de Girona. Consiste en una aplicación gratuita y sin ánimo de lucro, en forma de webapp, disponible en tres idiomas (castellanos, catalán e inglés), que incluye los puntos del PIJ del territorio (oficinas de farmacias comunitarias, centros básicos de salud, consultorios locales, hospitales, centros específicos de drogodependencias y centros de reducción de daños). El usuario puede escoger el radio de kilómetros alrededor de los cuales se incluirán los PIJ disponibles y la información relevante de cada uno de ellos como horarios, dirección, teléfono y un mapa vinculado a la aplicación Google Maps®. Una vez descargada por primera vez, la aplicación funciona sin necesidad de disponer de acceso a Internet (off-line). Además, el usuario puede comentar su experiencia sobre su uso de la aplicación y sobre el PIJ. Se puede observar la interface de la aplicación en la Figura 1.

La primera fase del proyecto fue revisar la literatura científica sobre el uso de las TIC (Calvo, Carbonell y Johnsen, 2019) y de redes sociales en-línea (Calvo y Carbonell, 2019) por parte de personas en riesgo o situación de exclusión social, incluyendo PCDVP. Estas revisiones indican altas potencialidades y pocos riesgos en el desarrollo de instrumentos eSalud y mSalud en colectivos socialmente
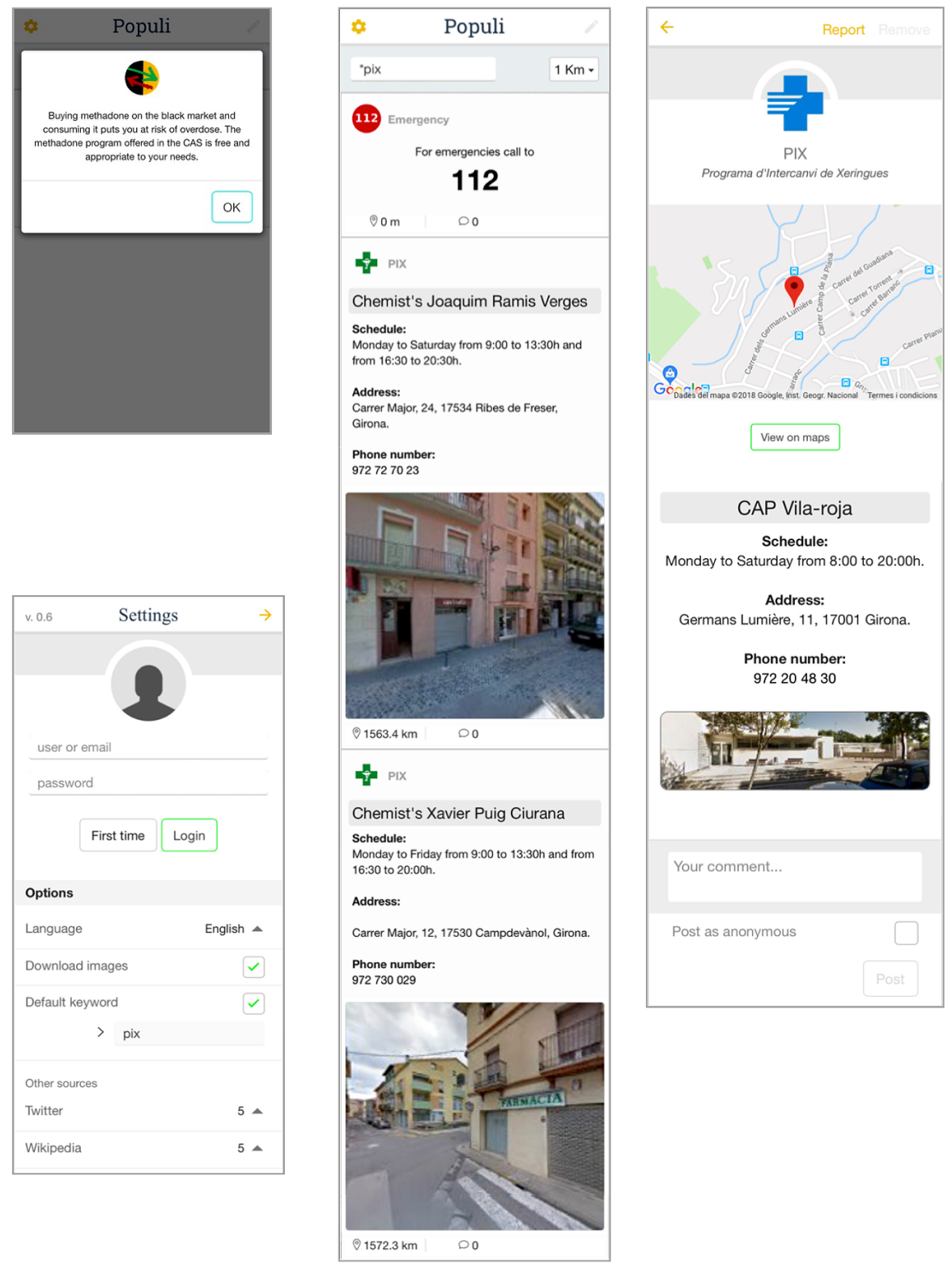

Figura 1. Interface definitiva de la aplicación en su versión en inglés. De izquierda a derecha: Primera columna: Ejemplo de consejo de salud y pantalla de ajustes. Segunda columna: Interface principal. Tercera columna: Información de un punto de intercambio de jeringas. 
vulnerables y con problemas de salud mental y/o adicciones. En una segunda fase y como estudio de viabilidad, durante el año 2016 se sondeó sobre el territorio el uso de TIC, Internet y teléfonos inteligentes de las PCDVP y se observó que el predominio, frecuencia y motivaciones de uso de personas en situación o riesgo de exclusión social extrema y PCDVP era similar al de la población general (Calvo, Carbonell, Turró y Giralt, 2018). Durante los meses de marzo a octubre de 2017 se diseñó la aplicación en formato de webapp descargable al escritorio del teléfono móvil desde cualquier navegador. Se escogió el formato webapp precisamente por su versatilidad técnica y su facilidad para actualizarse. Su primera versión fue testada en cuatro pruebas de usabilidad llevadas a cabo por 45 profesionales especialistas en adicciones, salud mental y otros servicios comunitarios de salud y 16 usuarios entre enero y marzo de 2018. Durante las pruebas de usabilidad los participantes probaron la app e hicieron sugerencias de mejora. Se llevaron a cabo cambios como resultado de dichas propuestas: i) se eliminaron las dos columnas de la interface principal porque los usuarios consideraban que era demasiado densa; ii) el consejo de salud aleatorio de la app aparecía en la interface principal en la primera versión y en forma ventana emergente en la segunda versión; y iii) se priorizó la información visual del mapa para geolocalizar la posición con respecto al punto PIJ a la información por escrito (horarios, teléfono, dirección). El proceso de las pruebas de usabilidad puede ser consultado en su totalidad en el trabajo previo de Calvo, Carbonell y Mundet (2020).

Desde septiembre de 2018 hasta febrero de 2019 se llevó a cabo la prueba piloto de la aplicación. Durante estos seis meses las PCDVP pudieron probarla sobre el terreno para finalmente participar en los grupos focales que evaluaron su experiencia. Para llevar a cabo esta prueba, un equipo de estudiantes de grado de educación social voluntarias, que recibieron un curso de capacitación a tal efecto, acudieron presencialmente a los PIJ del territorio. Se seleccionaron los puntos PIJ donde había más demanda de material de inyección. Estos ocho puntos del PIJ incluyeron el Centro de Atención Primaria de Vila-Roja de la ciudad de Girona, el punto que más material de inyección distribuyó en Catalunya en el año 2017 (Calvo et al., 2020) y un centro específico de atención a personas sin-hogar. Las voluntarias informaron sobre la existencia de la app, asesoraron sobre cómo descargarla y usarla e invitaron a usar la aplicación a las PCDVP. Durante la prueba piloto, la aplicación se descargó desde 97 dispositivos móviles que hicieron 297 consultas. La estimación del número de PCDVP en este territorio es de un total de 300 personas.

Los investigadores sondearon posibles candidatos para participar en los grupos focales de análisis del periodo de prueba de la app. A las PCDVP que acudían a estos servicios y habían probado la app se les ofreció la participación en los grupos. A medida que se disponía de un número que se consideraba suficiente para poder llevar a cabo el grupo y teniendo en cuenta el riesgo de abandono, se ofreció a grupos de 15 personas de cinco centros diferentes la posibilidad de participar. De las 75 PCDVP a las que se les ofreció participar, finalmente lo hicieron 51 (el 68\%).

Las 23 PCDVP que no quisieron participar en los grupos focales esgrimieron no estar en condiciones de hacerlo en el momento de la cita, no haberse acordado o tener otras responsabilidades. Se llegó al acuerdo de que no existía un perfil que pudiera aportar información sobre el tipo de PCDVP que no participaba en los grupos y sus motivos, su relación con la propuesta o el proyecto, ni tampoco con respecto al tipo de centro. Se puede consultar la secuencia descrita del estudio de creación, desarrollo y evaluación de la aplicación PixApp en la Figura 2.

\section{Recogida de datos}

Los grupos focales se formaron con un criterio de conveniencia. A su inicio, se solicitó a los participantes por escrito y de forma anónima su edad, sexo y la droga principal que se inyectaban. Se consultó en las bases de datos de los centros el resto de la información sociodemográfica (nivel de estudios, situación de vivienda y procedencia).

Durante el proceso, no se dieron circunstancias en las que se considerara que se debieran modificar las estrategias de recolección de datos atendiendo a que se consideró que se disponía de información de suficiente calidad como para dar respuesta a las preguntas de investigación.

Al iniciar cada grupo focal se les informó que la duración aproximada y que su colaboración sería muy útil para la aplicación, el territorio y el programa y, en término generales, para la comunidad clínica y científica. El total de los participantes manifestó su voluntad de colaborar con el equipo de investigadores.

Las sesiones de los grupos focales duraron entre 45 y 70 minutos, con una media de 58 minutos. Se intentó que la información fluyera de forma natural entre los participantes. Se utilizó la siguiente obertura: Todos vosotros y todas vosotras habéis participado de forma voluntaria en la prueba piloto de la aplicación del programa de intercambio de jeringas. Con este grupo quisiéramos evaluar qué os ha parecido esta aplicación en el uso diario; que os ha gustado más y pensáis que aporta la aplicación; que os ha gustado menos y creéis que no aporta nada o que debería mejorarse. Podéis hablar libremente de lo que penséis. Se trata de que podáis sinceraros para que nuestro equipo pueda valora el trabajo que ha hecho y mejorarlo si es necesario. Os quiero agradecer de nuevo vuestros esfuerzos estando aqui y recordaros que vuestra opinión es muy valiosa para la mejora de la app como del programa PIJ en general.

Después de esta introducción los investigadores mantenían el silencio tratando de que los participantes comenzaran a hablar. Cuando esto no era así, se formulaban dos preguntas abiertas: i) ¿Qué cosas positivas destacarías de la aplicación y de su uso en tu día a día? y ii) ¿Qué cosas negativas destacarías de la aplicación y que podrían mejorarse 


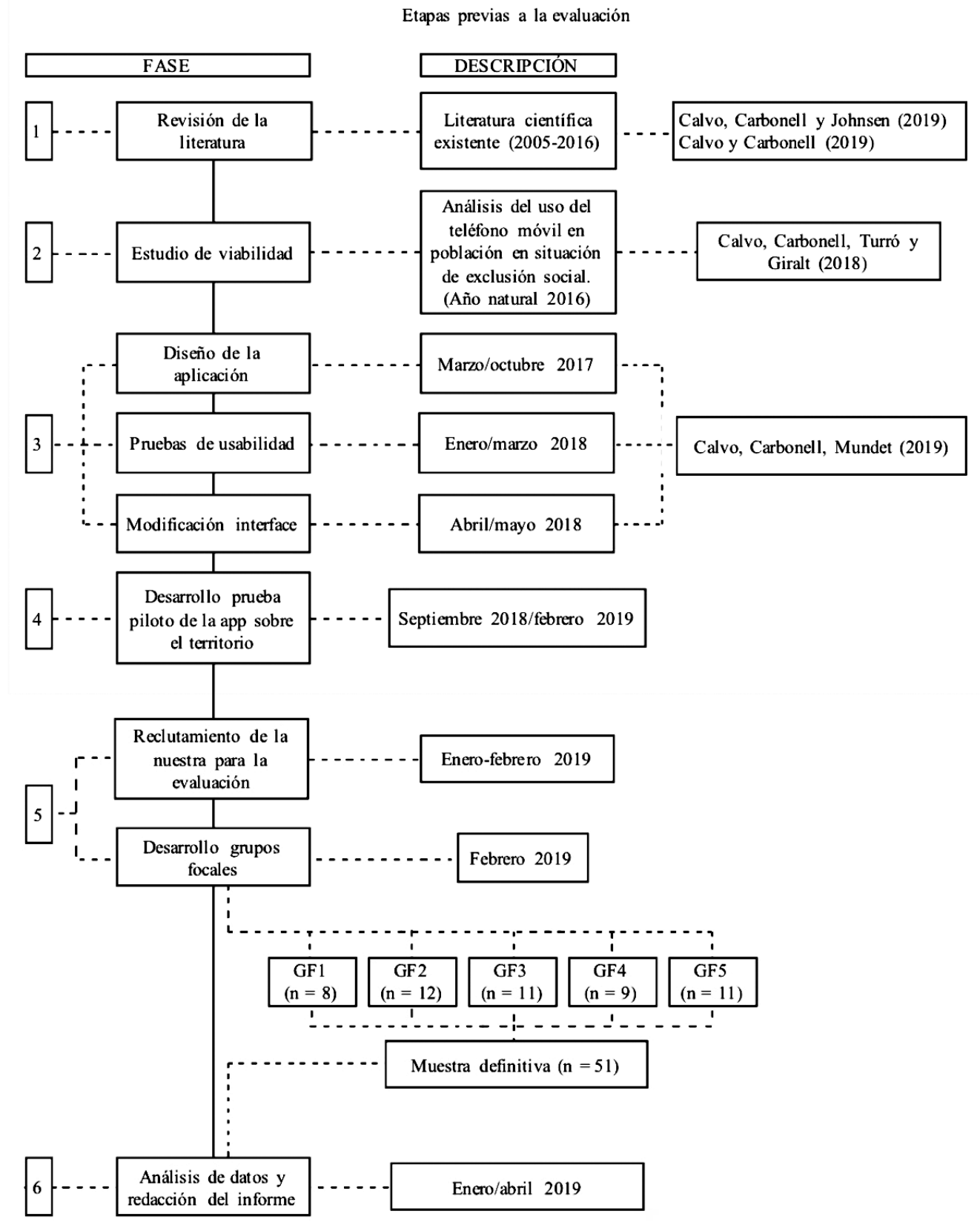

Figura 2. Diagrama de flujo de las fases del estudio.

para que respondiera a tus necesidades del día a día? Para para desencallar discursos circulares se hacían pequeñas síntesis de lo que se había dicho hasta el momento y se invitaba a hablar sobre un tema que hubiese quedado abierto previamente o se preguntaba si se quería ampliar alguna cuestión de la que se había tratado en poca profundidad. Los grupos se cerraron con un estímulo/cierre para agradecer a los participantes su presencia y colaboración.

Desde que se llevaron a cabo las pruebas de usabilidad con PCDVP, los investigadores hicieron un trabajo de reflexividad que abarcó todas las fases del proyecto (De la Cuesta-Benjumea, 2011), especialmente en la recolección de datos, la formulación de entradas y cierres como en las preguntas que se formularon durante su ejecución. Por ejemplo, la información que se extrajo del primer grupo focal fue examinada por los miembros del equipo de investigadores, concluyendo que el protocolo era acertado, no eran necesarias modificaciones y dotaba de garantías para poder llevar a cabo la investigación sin hacer aportaciones más allá de las descritas para motivar el discurso de los participantes.

Los grupos focales fueron registrados en formato de audio. Una vez finalizados, se transcribieron íntegramente. Posteriormente las transcripciones fueron importadas al programa Atlas Ti (séptima versión) para proceder a su análisis, atendiendo a la adecuación del programa informático para el diseño escogido (Hwang, 2007). 


\section{Análisis}

\section{Estrategias de análisis}

Se llevó a cabo el estudio cualitativo de enfoque descriptivo a partir del un análisis de contenido temático. El análisis temático permitió identificar, organizar y analizar patrones (temas) de forma minuciosa gracias a la lectura y relectura la información por parte del equipo de investigación (Braun y Clarke, 2006). Gracias a este método se identificaron algunas referencias cruzadas entre los temas que permitieron ser comparadas con el resto de unidades de análisis, conformando así la lista de códigos y temas, de forma gradual hasta llegar al acuerdo final de los investigadores (Alhojailan, 2012). La información se codificó de forma abierta, axial y selectiva (Strauss y Corbin, 1990) y se categorizó identificando los fragmentos textuales y relacionándolos con un código (abreviatura de una idea temática) (Gibbs, 2007).

Dos de los cinco temas fueron escogidos previamente por los investigadores y fueron introducidos con las preguntas definidas sobre beneficios y aspectos a mejorar de la app. Una vez analizados los datos y tras el proceso de reducción de datos, se acordaron tres códigos más (quince subcódigos en total) sobre su usabilidad, la experiencia del usuario, sus beneficios y aspectos a mejorar y su percepción de los PIJ, cada uno de estos códigos se corresponde con un tema y así se organizaron los resultados del estudio. Ver Tabla 2 .

Cuatro investigadores trabajaron autónomamente en el establecimiento de códigos y subcódigos poniendo en común en varias fases sus decisiones y llegando al consenso final. Posteriormente se analizaron los códigos también de forma independiente y posteriormente en equipo a fin de optimizar la fiabilidad del proceso (Saldaña, 2013). De esta forma se limitó el sesgo relacionado con el efecto de la perspectiva de los investigadores. Además, se llevaron a cabo siete reuniones, tanto presenciales como virtuales, para homogeneizar el análisis y contribuir a la calidad de contraste de todo el proceso. Una quinta persona supervisó de forma externa la investigación, llevando a cabo una auditoría transversal del proceso, garantizando la transparencia, la objetividad y fomentando el consenso de las unidades de análisis.

En los fragmentos transcritos incluidos en el apartado de resultados, se incluyeron aclaraciones encorchetadas y en cursiva debido al elevado uso de jerga de los participantes. No se encontraron contradicciones o discrepancias significativas que no se pudieran resolver en el proceso de análisis.

Esta investigación fue aprobada por el Comité de Ética en Investigación CEI-Girona con el código de XSO_2017 del 7 de junio de 2017. Los participantes fueron informados verbalmente y por escrito sobre los objetivos del estudio, su carácter voluntario, recibieron una hoja informativa y firmaron el consentimiento informado. Al finalizar su participación, recibieron una gratificación económica de 15 euros. Este manuscrito tuvo en cuenta los criterios de la American Psychological Association para la elaboración de investigaciones cualitativas (Levitt et al., 2018). El presente artículo se realizó siguiendo el modelo de informe de investigación de Fernández, Dema y Fontani (2019).

\section{Resultados}

\section{Primera parte: ¿Cómo usaron la aplicación los parti- cipantes?}

La mayor parte de los participantes entraron en contacto con la aplicación en las pruebas de usabilidad antes o durante la prueba piloto, con la ayuda de las voluntarias

Tabla 2. Clasificación de códigos.

\begin{tabular}{ll}
\hline Códigos & Subcódigos \\
\hline Tipo de uso de la app ${ }^{1}$ & $\begin{array}{l}\text { Uso prioritario } \\
\text { Motivos de uso } \\
\text { Frecuencia }\end{array}$ \\
Beneficios de la app respecto al PIj ${ }^{2}$ & $\begin{array}{l}\text { Reducción estigma } \\
\text { Mejora conocimiento puntos PIJ }\end{array}$ \\
& $\begin{array}{l}\text { Facilita anonimato } \\
\text { Mejora la planificación }\end{array}$ \\
Aspectos de la app que serían mejorables & Descarga \\
& Exceso Pop-Up \\
Usabilidad y experiencia de usuario & Interface clara \\
& Fácil e intuitiva \\
Percepciones gejo de salud & Participación
\end{tabular}

Nota. ${ }^{1}$ Aplicación. ${ }^{2}$ Programa de intercambio de jeringas. 
del proyecto que informaron y ayudaron a descargarla en sus dispositivos. En la siguiente secuencia de un grupo de hombres y mujeres de entre 30 y 47 años de edad, se muestra como comenzó el contacto con esta aplicación y el inicio de su uso.

Investigador: ¿Cómo fue cuándo empezasteis a usar la aplicación?

Usuario 1, 33 años: Cuando aquellas chicas [voluntarias] me la enseñaron. Cuando fui a buscar material [ $d e$ inyección] al ambulatorio y me las encontré en la puerta. Me dieron la información.

Usuario 2, 38 años: Me enseñaron a descargarla y a usarla. A mí, me sorprendió un poco al principio. Se la enseñé a mi novia nada más llegar a casa.

Usuario 1, 33 años: Yo también se la enseñé a mi pareja. Ella también tiene problema de estos [hace el gesto de inyectarse en el brazo].

Usuaria 1, 35 años: No hice mucho caso al principio, pero un día estaba aburrida y la empecé a tocar. Flipé [me sorprendió] bastante porque nunca había visto antes una aplicación así y enseguida se la enseñé a los colegas [amigos/conocidos].

(GF1, Hombres y mujeres de 30 a 47 años).

Tal y como se ha descrito en el procedimiento, un grupo de voluntarias enseñaron a pie de calle, en los puntos PIJ más activos del territorio, como descargar la aplicación. El usuario 2 y la usuaria 3 manifestaron su curiosidad ante la propuesta que les hacen estas voluntarias y dicha curiosidad motivó el inicio del uso. Como podemos apreciar, los participantes informaron a familiares y amigos de sus primeros contactos con la aplicación, generando formas de transmisión de información entre iguales, tan empleadas en la reducción de daños. Más allá de la singularidad inicial que transmite a los usuarios una aplicación que informa sobre los puntos del PIJ, en el siguiente fragmento se ejemplifica como el uso de la aplicación pasa de ser por mera curiosidad a dar respuesta a una necesidad.

Usuario 1, 37 años: La app quedó allí... en la pantalla... La verdad es que no la usé después de mirarla el primer día. Siempre voy a buscar las chutas [jeringas] al mismo sitio.

Usuario 2, 41 años: A mí me pasa lo mismo. Siempre voy al mismo sitio.

Usuario 3, 39 años: Sí pero un día llegué y estaba cerrado. Acababa de cerrar y me acordé de la aplicación. Me conecté y había una farmacia al ladito mismo. La verdad que me abrió un poco los ojos. Pensaba: "-Mira qué fácil-".

Usuario 4, 40 años: A mí me pasó igual. Miré la $a p p$ para ver si en mi pueblo había [puntos PIJ] y sí que ha- bía. De esta manera no tengo que estar bajando y subiendo [a otro municipio] para coger chutas.

Investigador: ¿Entiendo que el uso principal ha sido cuando no habéis encontrado jeringas en el punto principal?

Usuario 3, 39 años: Sí.

Usuario 4, 40 años: Sí. Eso ha sido muy importante. Amplía miras.

Usuario 3, 39 años: Sí, en otro momento yo hubiera usado alguna jeringuilla que tuviese por casa. Pero había una farmacia muy cerca y no lo sabía y al final bajé. Creo que era nueva en esto... en esto del intercambio.

(GF4, hombres de 36 a 45 años)

En este fragmento se aprecia que el investigador orientó a los usuarios para aclarar si se referían a un uso informativo de la aplicación cuando el punto del PIJ que usaban habitualmente no cubría sus necesidades. El último comentario del usuario 3 es especialmente relevante puesto que indica que tras haber encontrado su punto PIJ habitual cerrado utilizó la aplicación y descubrió puntos del PIJ que desconocía.

A continuación, se muestra un fragmento sobre el uso informativo de la aplicación y su frecuencia de uso.

Usuario 1, 40 años: Tener los horarios [de los puntos $P I J]$ a mano va muy bien.

Usuario 2, 32 años: Yo subo [ a consumir] una vez por semana y no tengo claro cuando cierran [el punto PIJ habitual]. Lo miré en la aplicación y es muy fácil. En Google me pierdo más.

Usuario1, 40 años: Es que yo paso de [no quiero] preguntar en el ambulatorio cuando cierran.

Usuario 3, 35 años: A mí se me olvida

Usuario 4, 28 años: A mí no me gusta. Tienes que esperar.

Usuario 5, 39 años: A veces tienen un montón de gente haciendo cola y no te vas a parar tú allí solo para preguntar los horarios con todo el mono [con síndrome de abstinencia] o colocado [intoxicado].

Usuario 1, 40 años: Además los horarios cambian cada dos por tres.

Usuario 2, 32 años: Estaba en casa por la noche, ya tranquilo, abrí la $a p p$ y vi que cerraban a las tres $[15 h]$ y pensé, me da tiempo.

(GF2, hombres y mujeres de 28 a 40 años).

De este fragmento se extrajeron diferentes elementos. En primer lugar, hace referencia a la necesidad de los usuarios de tener los horarios de los centros PIJ a su disposición y de tener esta información actualizada. También comentaron sus dificultades para encontrar esta información en un buscador ordinario y como la aplicación había facilitado esta tarea. Por otro lado, manifestaron sus dificultades para 
preguntar los horarios en el centro de atención primaria PIJ porque debían esperar mucho tiempo para hacer la consulta (se entiende por el comentario que debido a la presión asistencial ordinaria del centro) y a causa de su sintomatología de abstinencia o intoxicación.

\section{Segunda parte: Beneficios de la aplicación en el mar- co del Programa de Intercambio de Jeringas}

Los relatos de las PCDVP describieron su percepción sobre los beneficios que reportaba la aplicación. En primer lugar, los participantes destacaron que percibían la aplicación como un acto de normalización de los servicios de salud hacia ellos respecto el uso de las TIC. En los siguientes fragmentos se describen las percepciones sobre los beneficios relacionados con la normalización asociada al uso del teléfono móvil:

Investigador: ¿Qué beneficios tiene la aplicación? (...) ¿qué tiene de positivo?

Usuario 1, 51 años: Haberla inventado. Que hayan tenido la idea [Risas todos].

Usuaria 1, 33 años: Es verdad, nadie antes había pensado en nosotros.

Usuario 2, 38 años: Porque deben pensar que no usamos el móvil porque nos pinchamos.

Usuaria 1, 33 años: Eso son... ¿cómo se dice?... prejuicios. Somos personas normales con un problema muy gordo.

Usuario 3, 26 años: Te ven ahí tirado, buscándote la vida y deben pensar: Estos no usan el móvil.

Usuaria 2, 25 años: Deben pensar que no sabemos ni lo que es Internet [Risas todos].

Usuario 4, 36 años: Claro, es que, que me inyecte drogas y tenga este problema no quiere decir que no pueda tener un móvil como todo el mundo.

(GF3, hombres y mujeres de 25 a 51 años)

Como se aprecia en la respuesta del usuario 1, el primer beneficio que comentaron los participantes es que la aplicación se diseñó considerando a las PCDVP usuarios normalizados de la tecnología. Este elemento mueve un discurso bastante generalizado de los profesionales de la salud sobre el supuesto infra-uso de la tecnología de las personas en situación o riesgo de exclusión social y de las PCDVP. Las PCDVP refirieron percibir esta discriminación. A continuación, vemos otro ejemplo de una persona en situación de sinhogarismo:

Usuario 1, 42 años: Yo vivo en la calle y más de uno me ha mirado mal por mirar el móvil. Parece que te digan con la mirada que por el hecho de estar en la calle no tienes derecho a tener teléfono (...) Pero es que [el teléfono] te soluciona muchas cosas: puedes contactar con la familia, gratis, desde el WhatsApp con WiFi de algún sitio; lees noticias... libros... te entretienes... y pasas mejor el día (...) Si me tienen que localizar es más fácil (...) Siempre es lo último que he vendido cuando he tenido más problemas y es lo primero que he comprado después cuando he tenido dinero. Esta aplicación es lógica con mi realidad y es útil.

(GF1, hombres y mujeres de 30 a 47 años)

Otras de las mejoras percibidas por los participantes fue que la aplicación ampliaba su conocimiento de los puntos del PIJ del territorio. La mayor parte de los participantes refirieron encontrar el material de inyección en uno o dos puntos habituales, cercanos al lugar de compra de sustancias o al propio domicilio. En muchas ocasiones, explicaron que recorrían rutas concretas dependiendo de donde obtener una jeringuilla y en relación a los horarios de obertura de cada punto del PIJ. El hecho de tener más información también cambió la planificación del proceso de consumir:

Usuario 1, 32 años: El otro día estábamos (...) y yo juntos [se refiere al compañero sentado al lado] y le dije, ¿por qué no miras la aplicación a ver si hay algún sitio para pillar [recoger] chutas [jeringas] por aquí?

Usuario 2, 26 años: Es verdad, sí, sí. Ya habíamos tomado... pero necesitábamos más [se refiere al material de inyección].

Usuario 1, 32 años: Y pensamos mira, ya no hace falta que subamos [al punto PIJ habitual], aquí también tienen. Y entramos a pedir a la farmacia, y nos dieron y ya está.

(...)

Usuaria 1, 33 años: Yo flipé [me sorprendió] de la cantidad de sitios que dan jeringas.

Usuario 3, 42 años: Yo también flipé con que hubiese tantos sitios que hacían intercambio. No conocía muchos.

(GF5, hombres y mujeres de 26 a 45 años).

Usuario 1, 27 años: Lo primero es que me ayuda a saber dónde más puedo tener jeringas. Eso nadie me lo había dicho.

Usuario 2, 42 años: Sí, a mí tampoco.

Usuario 3, 39 años: No suele haber información sobre eso en el CAS [Centro público de tratamiento].

Usuaria 1, 25 años: Sí que hay información. Había un papel que venían los puntos de intercambio [ de jeringas]... nos los dio (...) [se refiere a un profesional de referencia] pero lo perdí enseguida.

Usuario 1, 27 años: Yo tenía un papel con los puntos de intercambio pero me acuerdo que una vez fui a una farmacia y me dijeron que ya no tenían. Que allí no hacían intercambio [de jeringas]. 
Usuaria 2, 33 años: Claro, con la aplicación esto no pasa: la abres y ahí están [los puntos del PIJ].

Usuario 2, 42 años: Y además te dice si está abierto en ese momento o no.

Usuario 4, 33 años: Y te dice los que están más cerca de tuyo, así no tienes que comerte la olla [preocuparte] o pegarte una pateada [caminata].

Usuario 5, 51 años: Eso también es importante... te ahorras un buen pateo [caminata].

(GF3, hombres y mujeres de 25 a 51 años).

Como podemos observar en el comentario del usuario 5, su percepción fue que en los centros de tratamiento no se proporcionaba información sobre los puntos del PIJ. Los participantes 1 y 2 indicaron que esa percepción no era correcta porque a ellos sí que les facilitaron los trípticos que la administración actualiza e imprime periódicamente. El último comentario del usuario 1 indica que en una ocasión pudo consultar esta información en papel y que al acudir al servicio en cuestión, no era ya un punto del PIJ. Por ello, los participantes percibieron como positivo disponer de una herramienta con información actualizada de los puntos del PIJ. El comentario del usuario 6 y el último comentario del usuario 3 refuerzan la importancia de la geolocalización de estos servicios puesto que, si la PCDVP tiene la experiencia de no encontrar material de inyección en determinados servicios, es poco probable que vuelva.

\section{Tercera parte: Aspectos mejorables de la aplicación}

Por otro lado, se instó a los participantes a expresar los elementos de mejora de la aplicación. Prácticamente en todos los grupos y de forma generalizada se percibió la dificultad para descargar la aplicación. Como se ha descrito, esta aplicación no es nativa sino que se trata de una webapp. Una vez se accede la primera vez a ella a través de un navegador, debe anclarse al escritorio utilizando un acceso directo. Una vez hecho esto, la aplicación funciona como una aplicación nativa, pero el proceso de descarga es muy diferente al de las aplicaciones nativas para dispositivos IOS o Android. Además, para que la funcionalidad de la aplicación sea optima, se debe permitir el uso del GPS del teléfono para geolocalizar los puntos del PIJ. En caso contrario, la aplicación no funciona.

Investigador: ¿Qué aspectos de la $a p p$ creéis que son mejorables?

Usuario 1, 40 años: ¿Qué cosas no nos gustan?

Investigador: Sí. Y que cosas pueden dificultar su uso, creéis que se pueden cambiar para que sean mejores, etcétera.

Usuario 1, 40 años: Lo de bajarla.

Usuario 2, 42 años: Descargarla.

Usuario 1, 40 años: Eso.
Usuario 3, 45 años: Es difícil seguir todas las instrucciones.

Usuario 4, 41 años: Te lía bastante. Ahora una cosa, ahora la otra.

Usuario 2, 42 años: ¿No sería más fácil descargarla como una aplicación cualquiera?

Usuario 5, 26 años: Ahora que ya sé descargarlas me cambiáis el sistema [risas todos].

Usuario 4, 41 años: Podría ser más fácil, la verdad.

Usuario 1, 40 años: Yo se lo intenté enseñar a uno... descargarla... y la verdad es que no fui capaz de seguir los pasos.

Usuario 2, 42 años: Yo la acabé buscando en la tienda de aplicaciones... pero no estaba...

Usuario 1, 40 años: La verdad es que sí. Ese es un punto que hay que cambiar porque si es difícil descargar al final la peña [gente] pasa, y al final no la usan.

(GF5, hombres y mujeres de 26 a 45 años).

Se percibe una contundencia destacable en la primera respuesta del usuario 1, lo que añadido al comentario final del usuario 2 que explica como trató de buscar la aplicación en una plataforma virtual de aplicaciones móviles, indica la confusión alrededor del proceso de descarga en el formato webapp. Los participantes estuvieron de acuerdo en que la aplicación tenía que simplificarse.

Un segundo elemento de mejora fue el exceso de información de las ventanas emergentes con consejos de salud. La aplicación ofrece un consejo de salud cada vez que el usuario abre la aplicación. Este consejo es aleatorio entre más de 25, como por ejemplo "Usa siempre jeringuillas limpias para tu consumo". Cada vez que los usuarios de la aplicación hacen una búsqueda aparece de nuevo la ventana emergente con un consejo. Los participantes consideraron excesiva esta información, tal y como queda reflejado en el siguiente fragmento de GF2:

Usuario 1, 35 años: Lo que molesta mucho es la pantalla esa automática.

Profesional: ¿El consejo de salud?

Usuario 1, 35 años: Bueno, no es que moleste siempre. Molesta que salga tanto.

Usuaria 1, 40 años: Esa que te aconseja... cosas.

Usuaria 2, 32 años: La idea es buena, pero cuando has entrado dos veces ya cansa.

Usuario 2, 37 años: Se tendría que limitar un poco.

Usuario 3, 39 años: Con uno cada vez ya vale.

Usuaria 1, 40 años: Es que si no al final es... ¿cómo se dice?... que no tiene el efecto... el efecto que toca.

(GF2, hombres y mujeres de 28 a 40 años).

El comentario final de la usuaria 1 incide en que un exceso de información puede tener un efecto disuasorio y que demasiados consejos de salud en forma de venta- 
nas emergentes es contraproducente. Sobre este no hubo opiniones contrarias destacables y los participantes consideraron que un único consejo al abrir la aplicación sería suficiente.

\section{Cuarta parte: Elementos concretos sobre usabilidad y experiencia del usuario}

Los participantes consideraron que la usabilidad de la aplicación en el contexto real de desarrollo era una propuesta sencilla y adecuada. Excepto los aspectos ya comentados, no consideraron que hubiese ninguna dificultad en el uso de la interfaz y se consideró que tenía un uso muy intuitivo. En algunos casos, los participantes refirieron la necesidad de familiarizarse con la aplicación para agilizar la búsqueda de puntos del PIJ cuando necesitaban material de inyección, pero atribuyeron esta necesidad como similar a la requerida para familiarizarse con otras aplicaciones móviles dirigidas a la población general.

Usuario 1, 39 años: Es fácil.

Usuario 2, 42 años: Súper fácil.

Usuario 3: Hombre, yo tuve que estar un rato mirando cómo funcionaba, la verdad.

Usuario 1, 39 años: ¡Pero eso es normal hombre! No puedes entrar y ya directamente ser un profesional... ¡habrá que estudiarla un poco! [Risas]

Usuario 3, 47 años: Es que yo os veía muy espabilados.

Usuario 2, 42 años: No, no... lo que pasa es que es fácil a la que dedicas un minuto a ver de qué va y cómo se usa. Después es un pim-pam [un momento].

(GF1, Hombres y mujeres de 30 a 47 años).

Por otro lado, los participantes tuvieron la percepción de que la aplicación podía ser una herramienta para comunicarse con los servicios de salud. La aplicación permite dejar comentarios de texto sobre la experiencia de los usuarios en la adquisición de material de inyección. Los participantes consideraron que esta prestación de la aplicación presentaba la potencialidad de favorecer la comunicación asincrónica con los servicios de salud, especialmente en cuanto a sus necesidades como personas con consumos activos de drogas.

Usuaria 1, 42 años: A veces no estás para hablar con nadie.

Usuario 1, 38 años: Es verdad.

Usuaria 1, 42 años: [En los servicios] Te paran para hablar, en verdad, (...) muchas veces te paran y tú no quieres pararte a hablar. Dices -¡Buah, ahora no!- pero poder tener una forma de contactar que no sea la cita de siempre, va bien. A veces estas todo rallado [rumiativo] con todo el bajón [lábil] y el móvil es lo único que tienes. A veces el que tienes al lado está peor que tú... yo que sé... son las dos de la mañana... todo puesto [intoxicado]... con quien vas a hablar... esto de tener otra forma [de contactar] es interesante. A veces lo pruebas con la familia... pero están hartos de ti.

$$
\text { (...) }
$$

Usuario 2, 32 años: A ver. Seamos sinceros. Y que nosotros no somos precisamente corderitos lechales [risas todos] (...) Que a veces también pasamos de todo. De esta manera a lo mejor ellos [los profesionales] también pueden usar la $a p p$ para decirnos cosas a nosotros.

(GF5, hombres y mujeres de 26 a 45 años).

Como hemos visto en el anterior extracto, la usuaria 1 identifica y describe la necesidad de poder acceder a un canal alternativo de comunicación. Este podría aumentar el rango de disponibilidad de los servicios de salud, más allá de las propuestas formales de citación presencial. Este hecho es especialmente relevante en los momentos en que el usuario percibe más necesidad comunicativa, en este caso porque acusa más el efecto negativo de su consumo activo y fuera de las horas habituales de la oferta ordinaria de intervención.

Por otro lado, el usuario 3 propone que la aplicación sea una herramienta de contacto de los servicios, algo muy relevante dada la dificultad para contactar con las PCDVP menos motivadas para comunicarse con los servicios.

\section{Quinta parte: Percepciones generales de los partici- pantes sobre el Programa de Intercambio de Jeringas}

Finalmente se recogieron las percepciones sobre el uso de la aplicación en el marco del desarrollo del PIJ y sobre cómo el uso de la tecnología podía influir en el desarrollo de un programa instaurado desde hace varias décadas. Los participantes destacaron que el uso de la aplicación podía contribuir a reducir el estigma social como personas ajenas al devenir de la sociedad $u$ otros intereses no relacionados con el consumo de drogas o su entorno. Los usuarios relataron situaciones en los que se sintieron juzgados por el hecho de disponer de dispositivos de telefonía móvil y como eso es percibido como una dificultad para el desarrollo de intervenciones eSalud específicas. Con el siguiente extracto se puede ejemplificar esta afirmación:

Usuario 1, 45, años: Bueno, yo quiero agradecer esta iniciativa que habéis tenido.

Usuario 2, 36 años: Está muy bien que nos hayáis llamado para dar nuestra opinión... No quiero parecer un pelota [adulador] [Risas].

Usuario 1, 45 años: (...) Ahora en serio, nadie se acuerda de nosotros... de que también tenemos teléfono y ordenador.

Usuario 2, 36 años: La gente se piensa que como soy yonqui no uso Internet y seguro que tengo más seguidores que ellos en el Insta [Instagram]. 
Usuario 3, 41 años: Me acuerdo de aquel (...) [se refiere a un profesional] que se sorprendió mucho de que tuviese un IPhone. Era viejo [el teléfono] pero se me quedó mirando ahí... como juzgándome... Me sentí juzgado... ¿Que no lo he robado, eh!... me dieron ganas de decirle. Al final me fui todo rallado [rumiativo].

Usuario 4, 40 años: Claro, si hay mucha gente que piensa así, que todos somos delincuentes, como van a hacer aplicaciones para nosotros...

Usuario 5, 41 años: A mí me hace sentir como más normal. Esto [ hace el gesto de inyectarse] es una enfermedad, ¿no? También tenemos derecho a usar esto [levanta el teléfono móvil].

(GF4, hombres de 36 a 45 años)

En su segundo comentario, el usuario 2 resalta el uso de Internet y de las redes sociales de las PCDVP. Ese comentario reivindica un uso de las redes sociales activo y considera que pese al estigma que pesa sobre él como persona inyectora podría ser mucho más activo en las redes sociales que las personas que no tienen esta problemática, la importancia que para él tiene el uso de estas redes sociales y, en cierto modo, la necesidad de aceptación de este uso normalizado de las TIC pese a su adicción. En su último comentario, el usuario 3 relata una situación en la que se sintió juzgado por usar el móvil y la percepción de atribución de actividad delictiva sobre la posesión de su dispositivo por esta persona. En ambos casos, los participantes consideraron que la aplicación contribuía a normalizarlos a través del uso de la tecnología, a reducir el asociado estigma y a considerarlos como sujetos activos en el desarrollo tecnológico como sujetos de la eSalud.

En otro orden de cosas, otros usuarios consideraron que la atribución que los profesionales hacían del uso de la tecnología de las PCDVP ayudaba a reducir barreras y contribuía a generar empatía. Es decir, considerar que ellos podían estar interesados en el uso de aplicaciones de salud específicas como esta, era un indicador de un cambio de percepción de los profesionales respecto las personas que se inyectaban, y los intereses de la tecnología de los propios profesionales era un nuevo interés común con potencialidad para generar dicha empatía. Veamos el siguiente ejemplo:

Usuario 1, 40 años: Pues yo en una farmacia [el $d e-$ pendiente] se interesó un montón en la aplicación... [el dependiente] ya lo sabía y hablamos... se portó bien... no sé... se interesó. Parecía más de tú a tú (...). Se puso ahí conmigo... cómo decir... codo con codo... pero de verdad... se puso a mi lado y parecía que él tenía más interés que yo... era un poco freaky [Risas]... No... quiero decir... pero freaky de la tecnología, vamos... que le gustaba la idea, vamos.

$(\ldots)$
Usuario 2, 41, años: Pues yo creo que eso hace que lo de ir a buscar una jeringa sea más normal. Es como cuando buscas un restaurante. No das tantas explicaciones.

Usuario 1: Falta que demos más nuestra opinión. Esto haría que la voz... bueno que estamos enfermos... que se escuchara más... no como yonquis... primero como personas.

Usuario 3, 45 años: Eso de dar la opinión está de puta madre [risas todos]. Es verdad... yo hablo claro, una cosa como la otra.

Usuario 4, 37 años: Así, si alguien me mira mal le hago así [el participante hace el gesto del pulgar hacia abajo en señal de desaprobación o "No me gusta" propio de las redes sociales] y punto negativo [risas todos].

Usuario 3, 45 años: Eso ayudaría a que nos tuviesen más en cuenta, ¿no? También somos clientes de un servicio. Es como si vas a un restaurante y un camarero te trata bien para que no le pongas una mala opinión en Internet. Como mínimo te trata bien por eso.

(GF4, hombres de 36 a 45 años)

Se aprecia que los participantes desarrollaron un discurso en el que se posicionaban como clientes de servicios de salud y atribuyeron a la aplicación la potencialidad de ser usada como canal comunicativo en el que dar su opinión como usuarios de dichos servicios, como sujetos activos de su salud con potestad para opinar sobre el servicio recibido. Su discurso también incidía en que el de la tecnología y la aplicación pueden contribuir a esta normalización.

\section{Discusión}

Esta es la primera investigación de la que se tiene constancia de una prueba piloto de una aplicación móvil de un programa de intercambio de jeringas. Se llevó a cabo un análisis cualitativo descriptivo, de análisis de contenido temático, a partir de cinco grupos focales en los que participaron cincuenta y una personas que consumían drogas inyectadas, disponían de teléfono móvil y accedieron en alguna ocasión a la aplicación durante los seis meses de testeo sobre el terreno. Los principales hallazgos indicaron una aceptación generalizada de la aplicación PixApp, que se consideró sencilla y útil, especialmente cuando los puntos de intercambio de material de inyección habituales estaban cerrados o no disponían de existencias de jeringas. Los participantes consideraron que la aplicación contribuía a reducir el estigma de las personas inyectoras, aumentaba el conocimiento de los PIJ del territorio, facilitaba el anonimato, mejoraba la planificación para disponer de material de inyección y podía contribuir a la normalización de la persona que consume drogas inyectadas como usuaria de tecnología eSalud. Entre los aspectos a mejorar, los participantes destacaron el exceso de consejos de salud 
en forma de ventanas emergentes y las dificultades para la descarga. Los participantes refirieron que la aplicación tenía potencial como canal de comunicación alternativo con los servicios de salud, especialmente cuando los usuarios percibían los momentos de más necesidad comunicativa y que los servicios no podían cubrir por motivos estructurales.

En España la evidencia científica sobre el uso de las TIC por las personas que se inyectan drogas y las posibilidades de desarrollar intervenciones de eSalud o de mSalud en esta población y contexto es escasa aunque prometedora (Calvo y Carbonell, 2018, 2019). En el plano internacional, las intervenciones educativas eSalud han demostrado eficacia para prevenir la infección del VIH y la Hepatitits-C incrementando el conocimiento de los canales de transmisión, modificando creencias erróneas sobre mecanismos de contagio y reduciendo las conductas sexuales de riesgo (Noar y Willoughby, 2012). Las aplicaciones específicas para la reducción de daños han demostrado potencialidad para reducir el efecto nocivo del consumo de alcohol (Milward, Deluca, Drummond y Kimergård, 2018) y para prevenir el riesgo de sobredosis (Baldacchino et al., 2016).

Hacer partícipes a los usuarios a quien va dirigida una herramienta de eSalud o mSalud para atender sus necesidades es una recomendación importante porque orienta sobre la funcionalidad de la herramienta en un contexto real, con una experiencia directa del usuario (Law y van Schaik, 2010) y dota de la posibilidad de modificarlas y adaptarlas en un proceso bidireccional de análisis y mejora continuada. De hecho, de ello depende en gran medida la aceptación por la población vulnerable, en riesgo o situación de exclusión social (Byrnes, 2016) ya que la penetración de las TIC en estas poblaciones requiere un acompañamiento que va más allá del aprovisionamiento de la tecnología y el acceso a Internet y debe tratar de ajustarse a las necesidades socioeconómicas de las personas a las que va dirigida, explorándolas de forma prospectiva y regular para tratar de mantener la continuidad de la conectividad (Kaba, 2018).

En el desarrollo de la webapp, los participantes refirieron que la aplicación contribuyó en la mejora de su planificación y medió en el proceso/ritual de conseguir la jeringa. El cambio de los patrones/rituales de consumo perjudiciales son, en gran medida, el contenido de las intervenciones socioeducativas en reducción de daños cuyo éxito depende de su aceptación y utilidad por y para los destinatarios (Calvo, Ribugent y Pontsa, 2015). La ansiedad asociada al deseo de consumir y el síndrome de abstinencia genera situaciones que los propios afectados describen como desesperadas e incrementan las prácticas de riesgo graves como el uso compartido de material de inyección (Castaño-Pérez y Calderón-Vallejo, 2010). Parece evidente que cuantas más dificultades tenga una PCDVP para acceder al material de inyección, más se incrementa este riesgo, ya que la planificación del consumo (y del material necesario para materializarlo) está potencialmente mediada por ese ritual, que en muchas ocasiones puede distar de una conducta protectora (Roth et al., 2015). Un ejemplo de ello es una situación habitual en la práctica clínica diaria en reducción de daños en la que las PCDVP adquieren antes la substancia que la jeringuilla esgrimiendo que lo contrario "trae mala suerte" o "despierta" el síndrome de abstinencia (Calvo-García, Turró-Garriga y Giralt-Vázquez, 2014). Si después de adquirir la dosis la PCDVP no dispone de un punto PIJ cercano, se incrementa el riesgo de reutilizar una jeringa. Las PCDVP refirieron acudir a los puntos del PIJ habituales pero si estaban cerrados o desabastecidos de material, el acceso a una información actualizada a través del teléfono móvil es una herramienta potencialmente eficaz para modificar el proceso de adquisición de material en el punto habitual y generó la percepción de mejorar la posibilidad de planificar el acceso a la jeringa.

De este modo, una información completa y actualizada de los PIJ del territorio y un canal apropiado para que esta información sea accesible para las PCDVP son la base para mejorar la cobertura de material de inyección que la Organización Mundial de la Salud considera insuficiente (OMS, 2016). El uso de panfletos informativos en papel es habitual pero su eficacia puede incrementarse. Los usuarios refirieron desconocer la existencia de dicha información y el riesgo de perderla o no recordarla. Los centros adscritos al PIJ se vinculan o desvinculan del mismo por diversos motivos, generando la necesidad de constante actualización de los directorios y bases de datos. Una demora en la transmisión de la información actualizada al usuario es un factor de riesgo cuyo impacto podría ser reducido por herramientas virtuales, a través de un canal, el del teléfono inteligente e internet, con el que el usuario está familiarizado. Los participantes consideraron que la aplicación contribuyó a reducir la brecha informativa entre el proveedor de salud y el usuario último, además de incluir información complementaria que las PCDVP consideraron adecuada como fotografías, horarios, dirección y teléfono, que facilitaban el contacto con el servicio.

Por otro lado, una de las funcionalidades de la aplicación es la posibilidad de dar consejos de salud en forma de mensajes de texto como ventanas emergentes, cada vez que el usuario navega por la interfaz. Los consejos de salud a través de dispositivos fijos o móviles han demostrado tener una importante capacidad preventiva (Mason, Ola, Zaharakis y Zhang, 2015). Pero si bien es cierto que la gran accesibilidad de los servicios de salud a los destinatarios a través de las TIC es una ventaja asociada a la ubicuidad de la tecnología, no lo es menos que un exceso de información preventiva no dosificada y adaptada a la capacidad de acomodación de la información de los usuarios puede ser contraproducente (Nation et al., 2003). Por otro lado, la webapp no se instala como una aplicación nativa y esta es 
una dificultad relevante que se salvó gracias a la ayuda de las voluntarias. Acompañar a los usuarios sobre el terreno es aconsejable cuando la población a la que va dirigida la tecnología se encuentra en situación o riesgo de exclusión social (Byrnes, 2016). De hecho, por muchas oportunidades que existan para reducir las barreras de acceso a la salud a través de las TIC es necesaria una adaptación continua a las capacidades de los usuarios (McInnes, Li y Hogan, 2013). No existiendo otros ejemplos de evaluaciones de aplicaciones para dispositivos móviles dirigidas a PCDVP, el estudio de Sheoran et al. (2016) que evaluó a partir de grupos focales el desarrollo de una app de geolocalización de servicios para jóvenes sin-hogar, concluyó que la aplicación contribuyó a reducir las barreras entre usuarios y proveedores de salud, a disminuir el estigma asociado a la exclusión social y a mejorar la percepción de las personas usuarias respecto los servicios sociosanitarios.

Finalmente, los participantes percibieron la aplicación como un elemento tecnológico que contribuía a reducir su estigma. En primer lugar, porque consideraron que mejoraba la percepción de los servicios sobre su problemática, normalizándonos a través de la impresión que los proveedores de servicios tenían de ellos como usuarios de las TIC. En segundo lugar, porque les permitía expresar su experiencia en el proceso de adquisición del material de inyección. Para las PCDVP la adquisición de la jeringa implica una relación con diversos agentes de salud que en ocasiones tienden a juzgar el comportamiento del inyector, contribuyendo a su estigmatización y reduciendo la capacidad preventiva de los programas de intercambio de jeringas con resultados adversos (Paquette, Syvertsen y Pollini, 2018). Los participantes refirieron que la posibilidad de explicar esta discriminación a los responsables de salud pública, los protegía y reducía la posibilidad de dicha estigmatización. Esta relación que posibilitan las tecnologías a los usuarios de servicios no es diferente en otros ámbitos en que el usuario de salud cada vez es más activo de su propia salud y tiene capacidad de mediar en los procesos de que son partícipes activos y, por lo tanto, de contribuir a la optimización de recursos y al ajuste de las necesidades últimas (Armayones et al., 2015). El hecho de aumentar la participación de las PCDVP es relevante a la par que necesario ya que tiene capacidad de contribuir a la inserción social y comunitaria, que a su vez presenta capacidad proactiva para reducir costes sanitarios, detectar nuevas necesidades más rápidamente y mejorar la atención e investigación.

Este estudio no está exento de limitaciones. En primer lugar, se accedió a una información sociodemográfica y clínica limitada, de una muestra de participantes y en un contexto concretos. Por ese motivo y aunque no es el objetivo de la investigación cualitativa generalizar los resultados, ya que describe un contexto, situación y participantes particulares, se debe tener en cuenta esta limitación y no generalizar sus resultados. Se recomendaría pues como vía futura de investigación, seguir indagando en el uso de la eSalud y la mSalud por parte de población de consumidores inyectores de drogas, especialmente de aquellos en situación o riesgo de exclusión social. Por otro lado, se consideró que esta información era suficiente para describir la población participante y se priorizó el uso del tiempo limitado de los grupos focales para tratar de dar respuesta a los objetivos del estudio, relacionados con la experiencia de los participantes con la aplicación. En segundo lugar, se debe tener en cuenta la posibilidad de que los participantes hubiesen respondido con un cierto grado de deseabilidad social pese a que se trató reducir este efecto solicitando su opinión sincera y generando un clima agradable en los grupos focales. En tercer lugar, los participantes recibieron una compensación económica por su participación, cosa que pudo mediar en su motivación para hacerlo, aunque este tipo de gratificaciones son habituales en estudios de salud con poblaciones en situación de exclusión social extrema y consumo inyectado de drogas, con el objetivo de facilitar el reclutamiento de la muestra y su retención. En cuarto lugar, no se ha evaluado el impacto de la aplicación en la distribución de material de inyección; este hecho orienta hacia una vía de investigación futura para analizar si el uso de la aplicación tiene capacidad de provocar cambios cuantitativos en número de kits de inyección distribuidos o en zonas geográficas de concentración de la actividad del PIJ. Por otro lado, hubiese sido útil acceder a otras fuentes de información, como por ejemplo el desarrollo de entrevistas individuales como complemento a los grupos focales, cosa que no fue posible a causa de las dificultades de retención de los participantes. De todos modos, consideramos que la información extraída de los grupos dotó de la suficiente información como para dar respuesta a las preguntas de investigación. Por otro lado, el número de mujeres participantes en el estudio fue muy limitado por lo que se recomienda aumentar el número de mujeres para poder incluir el género como variable mediadora. La perspectiva de género hubiera posibilitado el aprovechamiento de la dinámica de grupo focal para determinar las posibles relaciones entre diferentes grupos, de la misma forma que con otras características diferenciadoras, como la comparación entre las personas que usaron y no usaron la aplicación (por ejemplo, no se dispone información sobre las personas que no usaron la aplicación, por ejemplo porque no les pareció útil o no les gustó), pero las dificultades de acceso y retención de la muestra imposibilitaron el acceso a otras submuestras. Finalmente, este estudio está carente de la información necesaria para evaluar el impacto de la app en la cobertura del PIJ en términos cuantitativos y cualitativos, pero nos orienta hacia futuras vías de investigación relacionadas con ello.

En conclusión, la aplicación fue considerada como una herramienta de mSalud adecuada para su propósito, que es el de contribuir al acceso de personas que consumen 
drogas inyectadas a material de inyección. La percepción de los usuarios de la aplicación fue que es una herramienta fácil y accesible, con capacidad para contribuir a una planificación del consumo más protectora debido a la actualización de los puntos de intercambio. El exceso de información preventiva y al proceso de descarga se consideraron elementos a mejorar. Finalmente, los participantes sugirieron que la aplicación presenta potencialidad para reducir el estigma de los usuarios porque normaliza su uso de la tecnología como el de cualquier ciudadano y facilita la posibilidad de participar con los proveedores de salud indicando su opinión sobre su experiencia en el proceso de adquisición de material de inyección.

\section{Reconocimientos}

A los usuarios y usuarias de la aplicación que participaron en esta prueba piloto y nos dieron su valiosa opinión. A las voluntarias y voluntarios que colaboraron mostrando la aplicación a los usuarios: Inma Tineo, Marta García, Laura Rovira, Júlia Presas, Ana Martínez, Gemma Alonso, Félix Romero, Núria Martín, Sara Ramos y Marta Pera. A la Subdirecció General de Drogodependències del Departament de Salut de la Generalitat de Catalunya por dotar de parte de los fondos para la gratificación económica para los participantes en el estudio y apoyar el proyecto.

\section{Conflicto de intereses}

Fran Calvo es creador y codesarrollador de la aplicación al que se refiere el artículo junto con el ingeniero informático José Núñez de la que son copropietarios. Esta aplicación surge de necesidades detectadas en la práctica profesional en un servicio público, el Institut d'Assistència Sanitària de Girona y se trata de un programario sin ánimo de lucro, cuyo objetivo es mejorar el acceso de material de inyección a personas que consumen drogas inyectadas. Xavier Carbonell, Mercè Rived y Cristina Giralt declaran la ausencia de cualquier conflicto de intereses.

\section{Referencias}

Alhojailan, M.I. (2012). Thematic analysis: A critical review of its process and evaluation. West East Journal of Social Sciences, 1, 39-47.

Armayones, M., Boixadós, M., Gómez, B., Guillamón, N., Hernández, E., Nieto, R.,... Sara, B. (2015). Psicología 2.0: Oportunidades y retos para el profesional de la psicología en el ámbito de la salud. Papeles del Psicólogo, 36, 153-160.

Baldacchino, A., Crocamo, C., Humphris, G., Neufeind, J., Frisher, M., Scherbaum, N. y Carrà, G. (2016). Decision support in addiction: The development of an e-health tool to assess and prevent risk of fatal overdose. The
ORION Project. Computer Methods and Programs in Biomedicine, 133, 207-216. doi:10.1016/j.cmpb.2016.05.018.

Bosque-Prous, M. y Brugal, M. T. (2016). Intervenciones de reducción de daños en usuarios de drogas: Situación actual y recomendaciones. Gaceta Sanitaria, 30, 99-105. doi:10.1016/j.gaceta.2016.04.020.

Braun, V. y Clarke, V. (2006). Using thematic analysis in psychology. Qualitative Research in Psychology, 3, 77-101. doi:10.1191/1478088706qp063oa.

Buti, M., Calleja, J. L., García-Samaniego, J., Serra, M. A., Crespo, J., Romero, M.,... Robbins, S. (2017). Eliminación de la hepatitis C en España: Adaptación de un modelo matemático de salud pública partiendo del plan estratégico para el abordaje de la hepatitis C en el Sistema Nacional de Salud. Medicina Clinica, 148, 277-282.

Byrnes, M. (2016). Text4baby mHealth Program: Implementation and applicability within a homeless population of young mothers. International Journal of Communitcation and Health, 8, 45.

Calvo-García, F., Turró-Garriga, O. y Giralt-Vázquez, C. (2014). El consumo activo de drogas de pacientes incluidos en un programa de tratamiento de mantenimiento con metadona. Revista de Trabajo Social y Salud, 79, 57-68.

Calvo, F. y Carbonell, X. (2018). Using Facebook for improving the psychological well-being of individuals experiencing homelessness: Experimental and longitudinal study. JMIR Mental Health, 5, e59. doi:10.2196/ mental.9814.

Calvo, F. y Carbonell, X. (2019). Is Facebook use healthy for individuals experiencing homelessness? A scoping review on social networking and living in the streets. Journal of Mental Health 28, 505-519. doi:10.1080/09638 237.2019.1608927.

Calvo, F., Carbonell, X. y Johnsen, S. (2019). Information and communication technologies, eHealth and homelessness: A bibliometric review. Cogent Psychology, 6, 1631583. doi:10.1080/23311908.2019.1631583.

Calvo, F., Carbonell, X. y Mundet, C. (2020). Developing and testing the Populi Needle Exchange Points Finder: An app to reduce harm associated with intravenous drug consumption among homeless and non-homeless drug users. Frontiers in Public Health, 8, 493321. doi:10.3389/ fpubh.2020.493321.

Calvo, F., Carbonell, X., Turró, O. y Giralt, C. (2018). Connected in the street: The relation between online social networks, selfesteem and satisfaction with life among individuals experiencing homelessness. Aloma, 36, 21-28.

Calvo, F., Mundet, C., Gonzalvo, B., Terrades, J., Cabarrocas, S., Giralt, C.,... Carbonell, X. (2019). Análisis del programa de intercambio de jeringuillas de la región sanitaria de Girona. Revista Comunidad, 21, 5.

Calvo, F., Ribugent, I. y Pontsa, O. (2015). Valoración psiquiátrica involuntaria e ingreso no programado de 
usuarios sin-hogar: Estudio de casos desde la educación social y la psicología. Revista de Educación Social, 20, 1-27.

Castaño-Pérez, G. y Calderón-Vallejo, G. A. (2010). Consumo de heroína en Colombia, prácticas relacionadas e incidencia en la salud pública. Revista Cubana de Salud Pública, 36, 311-322.

De la Cuesta-Benjumea, C. (2011). La reflexividad: Un asunto crítico en la investigación cualitativa. Enfermería Clínica, 21, 163-167.

Elattabi, M., Ruiz-Algueró, M., Hernando, V. y Díaz, A. (2017). Vigilancia epidemiológica del VIH/sida: Situación en Europa y en España, 2015. Boletín Epidemiológico semanal, 24, 147-152.

Eysenbach, G. (2001). What is e-health? Journal of Medical Internet Research, 3, e20. doi:10.2196/ jmir.3.2.e20.

Fernández, M., Dema, S. y Fontanil, Y. (2019). La influencia de los roles de género en el consumo de alcohol: Estudio cualitativo en adolescentes y jóvenes en Asturias. Adicciones, 31, 260-273. doi:10.20882/adicciones.1003.

Flick, U. (2004). Introducción a la investigación cualitativa. Madrid: Ediciones Morata.

Folch, C., Casabona, J., Espelt, A., Majó, X., Meroño, M., Gonzalez, V.,... Group, R. S. (2016). High prevalence and incidence of HIV and HCV among new injecting drug users with a large proportion of migrants. Is prevention failing? Substance Use $\mathcal{E}$ Misuse, 51, 250-260. doi:10.3109/10826084.2015.1092991.

Fuente, L., Brugal, T., Domingo-Salvany, A., Bravo, M. J., Neira-León, M. y Barrio, G. (2006). Más de treinta años de drogas ilegales en España: Una amarga historia con algunos consejos para el futuro. Revista Española de Salud Pública, 80, 505-520.

Gibbs, G. R. (2007). Analyzing qualitative data. Thousand Oaks, CA: Sage Publications.

Grebely, J., Larney, S., Peacock, A., Colledge, S., Leung, J., Hickman, M.,... Lynskey, M. (2019). Global, regional, and country-level estimates of hepatitis $\mathrm{C}$ infection among people who have recently injected drugs. Addiction, 114, 150-166. doi:10.1111/add.14393.

Hwang, S. (2007). Utilizing qualitative data analysis software: A review of ATLAS.ti. Social Science Computer Review, 26, 519-527. doi:10.1177/0894439307312485.

Kaba, B. (2018). Modeling information and communication technology use continuance behavior: Are there differences between users on basis of their status? International Journal of Information Management, 38, 77-85. doi:10.1016/J.IJINFOMGT.2017.08.007.

Kay, M., Santos, J. y Takane, M. (2011). mHealth: New horizons from health though mobile technologies. World Health Organization, 64, 66-71. Recuperado de https:// www.who.int/goe/publications/goe_mhealth_web.pdf.

Law, E. L.C. y van Schaik, P. (2010). Modelling user experience. An agenda for research and practice. Inte- racting with Computers, 22, 313-322. doi:10.1016/j.intcom.2010.04.006.

Levitt, H. M., Bamberg, M., Creswell, J. W., Frost, D. M., Josselson, R. y Suárez-Orozco, C. (2018). Journal article reporting standards for qualitative primary, qualitative meta-analytic, and mixed methods research in psychology: The APA publications and communications board task force report. American Psychologist, 73, 26. doi:10.1037/ amp0000151.

Mason, M., Ola, B., Zaharakis, N. y Zhang, J. (2015). Text messaging interventions for adolescent and young adult substance use: A meta-analysis. Prevention Science, 16, 181-188. doi:10.1007/s11121-014-0498-7.

Morgan, D. L. y Krueger, R. A. (eds.) (1989). The focus group kit (6 vols). Thuosand Oaks: CA: Sage.

McInnes, D. K., Li, A. E. y Hogan, T. P. (2013). Opportunities for enganging low-income, vulnerable populations in health care: A systematic review of homeless persons' access to and use of information technologies. American Journal of Public Health, 103, 11-20.

Milward, J., Deluca, P., Drummond, C. y Kimergård, A. (2018). Developing typologies of user engagement with the BRANCH alcohol-harm reduction smartphone app: Qualitative study. JMIR mHealth and uHealth, 6, e11692. doi:10.2196/11692.

Nation, M., Crusto, C., Wandersman, A., Kumpfer, K. L., Seybolt, D., Morrissey-Kane, E. y Davino, K. (2003). What works in prevention. Principles of effective prevention programs. American Psychologist, 58, 449. doi:10.1037/0003-066X.58.6-7.449.

Noar, S. M. y Willoughby, J. F. (2012). eHealth interventions for HIV prevention. AIDS Care, 24, 945-952. doi:10.1080/09540121.2012.668167.

Page, K., Morris, M. D., Hahn, J. A., Maher, L. y Prins, M. (2013). Injection drug use and hepatitis $C$ virus infection in young adult injectors: Using evidence to inform comprehensive prevention. Clinical Infectious Diseases, 57, 32-38. doi:10.1093/cid/cit300.

Paquette, C. E., Syvertsen, J. L. y Pollini, R. A. (2018). Stigma at every turn: Health services experiences among people who inject drugs. International Journal of Drug Policy, 57, 104-110. doi:10.1016/J.DRUGPO.2018.04.004.

Platt, L., Minozzi, S., Reed, J., Vickerman, P., Hagan, H., French, C.,... Hickman, M. (2018). Needle and syringe programmes and opioid substitution therapy for preventing HCV transmission among people who inject drugs: Findings from a Cochrane review and meta-analysis. Addiction, 113, 545-563. doi:10.1111/add.14012.

Quintana, A. y Montgomery, W. (Eds.) (2006). Psicología: tópicos de actualidad. Lima: UNMSM.

Riper, H., Hoogendoorn, A., Cuijpers, P., Karyotaki, E., Boumparis, N., Mira, A.,... Smit, J. H. (2018). Effectiveness and treatment moderators of internet interventions for adult problem drinking: An individual patient 
data meta-analysis of 19 randomised controlled trials. PLOS Medicine, 15, e1002714. doi:10.1371/journal. pmed.1002714.

Rodriguez-Gómez, G., Gil-Flores, J. y Garda-Jiménez, E. (1996). Metodología de la investigación cualitativa. Granada: Aljibe.

Roth, A. M., Armenta, R. A., Wagner, K. D., Roesch, S. C., Bluthenthal, R. N., Cuevas-Mota, J. y Garfein, R. S. (2015). Patterns of drug use, risky behavior, and health status among persons who inject drugs living in San Diego, California: A latent class analysis. Substance Use E Misuse, 50, 205-214. doi:10.3109/10826084.2014.962661.

Saldaña, J. (2013). The coding manual for qualitative researchers. London: SAGE.

Sheoran, B., Silva, C. L., Lykens, J. E., Gamedze, L., Williams, S., Ford, J. V. y Habel, M. A. (2016). YTH StreetConnect: Development and usability of a mobile app for homeless and unstably housed youth. JMIR mHealth and uHealth, 4, e82. doi:10.2196/mhealth.5168.

Stone, K. (2018). The global state of harm reduction 2018. London. Recuperado de https://www.hri.global/global-state-harm-reduction-2018.

Strauss, A. L. y Corbin, J. M. (1990). Basics of qualitative research: Grounded theory procedures and techniques. Newbury Park, CA: Sage Publications.

World Health Organization. (2016). Estrategia mundial del sector de la salud contra las hepatitis víricas 2016-2021. Hacia el fin de las hepatitis víricas. Geneva: OMS. Recuperado de http:/ /apps.who.int/iris/bitstream/10665/250578/1/ WHO-HIV-2016.06-spa.pdf?ua=1.

World Health Organization. (2017). Global hepatitis report 2017. Geneva: WHO. Recuperado de https:/ /apps.who. int/iris/bitstream/handle/10665/255016/9789241565 455-eng.pdf. 
